\title{
Impact Of Storage On Iodine Stability Of Commercial Salt Brands
}

\author{
Emmanuel J. Ekott, Ubong I. Etukudo
}

\begin{abstract}
Potassium iodate (KIO3) is mostly added to table salts to prevent iodine deficiency disorders. In many cases iodine is lost from salt due to instability resulting in decreased levels in human diet, which give rise to a number of clinical problems. The effect of storage duration at room temperature on the stability of potassium iodate in commercial salts was investigated by iodometric titration. Dangote Salt and Mr. Chef Salt brands produced in Nigeria and initially fortified with $50 \mathrm{ppm} \mathrm{KIO3}$ were used in this study. Dangote Salt is found to be relatively more stable than Mr. Chef Salt, because after every 24 hours, the rate at which Mr. Chef Salt lost iodate is greater than Dangote. After 120 days exposure to room temperature Dangote salt lost $92.8 \%$ of its original iodine against $100 \%$ lost by $\mathrm{Mr}$. Chef salt brand. This difference in loss rate and stability is a reflection of the difference in the methods used in binding iodate to salts by the manufacturers. Table salts should be fortified with iodate using appropriate method and sealed properly during storage to enhance iodate stability, for the prevention of possible deficiency disorders.
\end{abstract}

Index Terms - Iodine, stability, salt, potassium iodate.

\section{INTRODUCTION}

Iodine is an important micro-nutrient required by every human for good health and well-being. The World Health Organization (1996) stated that inadequate intake of iodine in human diet has resulted into some clinical problems or Iodine Deficiency Disorders (IDDs); common examples are poor mental and physical development in children and goiter in adults (Hassanien et. al, 2003). Goiter is one of the most common endocrine diseases that affect between 200 million to 300 million people in the world (Fasanmade, 2019). The disease is seen as second most common endocrine disease, with limited information and awareness about its prevention, treatment, management and eradication in Nigeria (Ofortube, 2019). Iodine can be obtained from natural food materials milk, vegetables, fruits, cereals, eggs, meat, spinach and sea foods - however, these sources supply only low concentrations that are inadequate to meet the body's daily requirements to maintain good health, especially in pregnant women and young children (Bourre and Paquotte, 2008; Zimmermann, 2009). Ofortube (2019) recommends regular thyroid checkups for early detection of the disease.

The consumption of more carbohydrate rich food and milk than iodine increases ones chances of contracting thyroid disease (Fasanmade, 2019). In Nigeria the disease is under reported due to misdiagnosed cases. The result is the dearth of awareness, unavailability of standard and affordable medical facilities, scarcity of medical experts, policy action from

Emmanuel J. Ekott, Department of Chemistry, Heritage Polytechnic, Eket, Nigeria

Ubong I. Etukudo, Department of Chemistry, Heritage Polytechnic, Eket, Nigeria government and relevant stake holders (Ofortube, 2019). Studies on functioning of iodine revealed that the daily intake of iodine compound by an individual should be approximately $500 \mu \mathrm{g}$, of which about $120 \mu \mathrm{g}$ are taken up by the thyroid gland for the synthesis of thyroid hormones - which regulate some metabolic processes within the body (Khurana, 2006). Similarly, Fasanmade (2019) opined that the recommended dietary allowance for iodine is $50 \mathrm{cg}$ daily, while the optimal quantity is between 100 to $150 \mathrm{cg}$ daily.

More than half of the world's population receives less iodine than required for developing and maintaining good health through natural sources (Delange et. al, 2002). Fasanmade (2019) stated that $75 \%$ of thyroid disease is due to iodine deficiency. People who leave in riverine areas consume less than 50cg of salt daily. Such areas are goiter endemic and congenital hypothyroidism is common, with symptoms like fatigue, lethargy, cramps, cold intolerance, constipation and dry skin. It has therefore, become a global practice to fortify edible salts with potassium iodate, to reduce clinical problems resulting from iodine deficiencies.

Adequate iodine intake is provided by consumption of iodized salt. Salt is adopted in many countries as an iodine carrier of choice because it is consumed at relatively constant, well-definable levels by people within the society regardless of socio-economic status (Diosady, 1998).

A common problem among salt manufacturers and consumers is that fortified edible salts loose iodine due to sublimation before it is consumed. This loses is further enhanced when impurities are present in the salt. Storage conditions, distribution, food processing and cooking processes have been reported to affect the stability of iodine in salt (Bourre, 2008).

Other factors are uneven iodine quantities added to salt during production, uneven iodine distribution within the salt batches/bags due to improper mixing, losses during transportation, selling in retail, storage condition, meal preparation, light, impurities in the salt, alkalinity or acidity, chemical form of the iodine, moisture content of the salt, humidity of the atmosphere and heat. Ekott and Etukudo (2017) reported that high temperature is an important factor that affects the stability of salt iodine. WHO, UNICEF, and the international council for the control of iodine deficiency disorders (ICCIDD), in 1996, jointly admitted that salt loses iodine easily, as about $20 \%$ of salt iodine is lost from production to a household, and another $20 \%$ is lost during cooking prior to consumption.

\section{METHODS.}

Iodometric titration was used as the analytical procedure for this work, as described by Jooste and Strydom (2010). The salt samples used for this study were collected immediately after manufacture and safely transported to the laboratory in 
order to minimize iodine losses. Dangote Salt and Mr. Chef Salt brands are most commonly consumed among households in Nigeria, and were the salt brands used in this study.

\section{Iodometric Titration}

$10 \mathrm{~g}$ of salt sample was dissolved in $50 \mathrm{ml}$ of distilled water, and swirled to dissolve salt sample completely. $1 \mathrm{ml}$ of $\mathrm{H}_{2} \mathrm{SO}_{4}$ was added to liberate free iodine from the dissolved salt sample. $5 \mathrm{ml}$ of $10 \%$ potassium iodide was added to the flask to dissolve free iodine since the liberated iodine is insoluble in pure water. The reaction that occurred during this process is shown in equation 1.

$$
\mathrm{KIO}_{3}+5 \mathrm{KI}+3 \mathrm{H}_{2} \mathrm{SO}_{4} \rightarrow 3 \mathrm{~K}_{2} \mathrm{SO}_{4}+3 \mathrm{I}_{2}+3 \mathrm{H}_{2} \mathrm{O} \quad[1]
$$

The solution turned yellow indicating the presence of iodine in the salt. The flask was immediately stoppered and preserved in a dark closet (drawer) for at least 10 minutes before titration. This was done to avoid any photochemical reaction that could cause iodide ions to be oxidized to iodine when the solution is exposed to radiation.

The titration set up was put in place and via a glass funnel, some thiosulfate $\left(\mathrm{Na}_{2} \mathrm{~S}_{2} \mathrm{O}_{3}\right)$ solution was transferred into a clean burette and its level adjusted to zero point. After 10 minute the flask was removed from the dark closet and some $\mathrm{Na}_{2} \mathrm{~S}_{2} \mathrm{O}_{3}$ was added from the titration burette until the solution turned pale yellow. Approximately $2 \mathrm{ml}$ of the starch indicator solution was then added to the flask. The starch/iodine complex yielded a dark-purple colored solution. Further titration continued until the solution became pink and finally colorless. The process was repeated thrice so as to obtain an average $\mathrm{Na}_{2} \mathrm{~S}_{2} \mathrm{O}_{3}$ value consumed by the salt. The amount of sodium thiosulfate consumed is proportional to the amount of iodine liberated from the salt, as shown in equation 2.

$2 \mathrm{Na}_{2} \mathrm{~S}_{2} \mathrm{O}_{3}+\mathrm{I}_{2} \rightarrow 2 \mathrm{NaI}+\mathrm{Na}_{2} \mathrm{~S}_{4} \mathrm{O}_{6}$

\section{RESULTS AND DISCUSSION.}

During iodometric titration salts consume thiosulfate equivalent to the level of iodine present in it. The average amounts of thiosulfate consumed by the two salt brands with respect to time, at room temperature are presented in table 1 . A close comparison reveals that at every 24 hours interval, Dangote salt consumed more quantities of thiosulphate than Mr. Chef salt. This indicates greater iodate stability in Dangote salt brand.

Table 1. Average amounts of thiosulphate consumed by salts.

\begin{tabular}{|c|c|c|}
\hline $\begin{array}{c}\text { TIME } \\
\text { (HOURS) }\end{array}$ & DANGOTE SALT & MR. CHEF SALT \\
\hline & $\begin{array}{c}\text { AVERAGE VOLUME } \\
\text { OF NA } \mathbf{S}_{\mathbf{2}} \mathbf{O}_{\mathbf{3}} \\
\text { CONSUMED }\left(\mathbf{C M}^{3}\right)\end{array}$ & $\begin{array}{c}\text { AVERAGE VOLUME } \\
\text { OF NA } \mathbf{S}_{\mathbf{2}} \mathbf{O}_{\mathbf{3}} \\
\left.\text { CONSUMED }^{\text {CONM }} \mathbf{C M}^{3}\right)\end{array}$ \\
\hline 0 & 6.75 & 6.85 \\
\hline 24 & 4.80 & 3.65 \\
\hline 48 & 3.90 & 2.80 \\
\hline 72 & 3.55 & 1.90 \\
\hline 96 & 1.70 & 1.00 \\
\hline 120 & 0.50 & 0.00 \\
\hline
\end{tabular}

The level, and thus, stability of iodine in the studied salt brands after every 24 hours is calculated and plotted in figure 1. The equation that relates iodine level and the average volume of $\mathrm{Na}_{2} \mathrm{~S}_{2} \mathrm{O}_{3}$ consumed was given by Srivastava (2006) as:

lodine $($ ppm $)=\frac{(R \times 100 \times 1000 \times 0.127 \times N)}{6}$

Where $\mathrm{R}=$ Average volume of $\mathrm{NA}_{2} \mathrm{~S}_{2} \mathrm{O}_{3}, \mathrm{~N}=$ Normality of thiosulphate solution $(0.005 \mathrm{~N}), 100$ is to convert the reading for $100 \mathrm{~g}$ of salt, 1000 is to convert grams of iodine to milligrams of iodine, 0.127 is the weight of iodine equivalent of $1 \mathrm{ml}$ of normal thiosulphate solution, 6 is to arrive as the value that corresponds to 1 atom of iodine liberated.

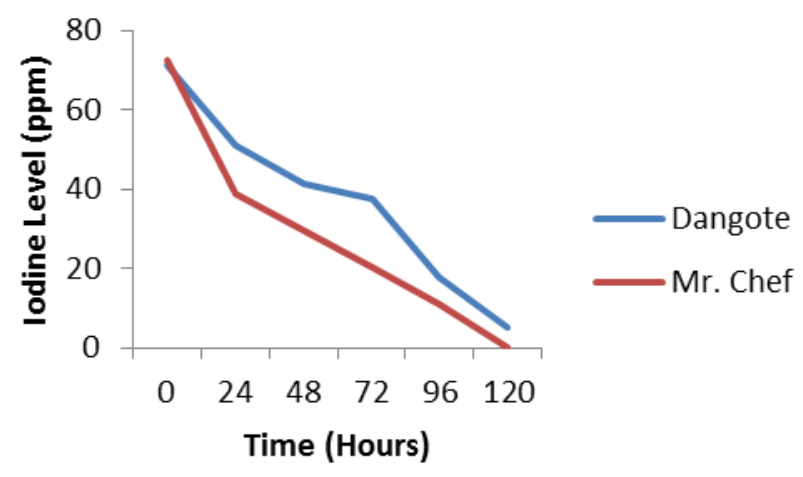

Figure 1: Iodine level (stability) in salts after every 24 hours.

As mandated by the World Health Organization, salt manufactures in Nigeria fortify edible salts with at least $50 \mathrm{ppm}$ of iodine. The studied salt brands were adequately fortified with iodate beyond 50ppm. As shown in figure 1, initial iodine levels of 71.4ppm and 72.4ppm were recorded for Dangote and Mr. Chef salt brands respectively, but, after 24 hours of exposure the initial iodine levels, in Dangote and Mr. Chef salt brands reduced to $50.8 \mathrm{ppm}$ and $38.6 \mathrm{ppm}$ respectively. At these levels, unlike $\mathrm{Mr}$. Chef salt, the iodate in Dangote salt is of greater stability because it is within the threshold stipulated by WHO for the prevention iodine deficiency disorders.

Similar result trend was obtained on subsequent analysis, but the iodine levels were below the WHO's accepted level. After 48 hours, Dangote salt maintained its greater iodate stability over Mr. Chef salt, 41.2ppm and 29.6ppm were recorded for both brands. Over 50\% iodine was lost by Dangote salt after 72 hours, but Mr. Chef lost over $70 \%$ at the same duration. Unlike, Mr. Chef Salt that lost $100 \%$ of its iodate at 120 hours, Dangote Salt retained 7.2\% (5.2ppm). This implies that the iodate in Dangote salt is relatively more stable, which may depend on the method employed in binding potassium iodate to salt, by the manufacturers. Thus, Dangote Salt is a brand of choice when the salt is to be used over a long period of time, although the loss of iodine in salts can be reduced when the conditions that favors iodate loss is checked. This result implies that iodized salts lose iodine when exposed to the atmosphere over time (even at room temperature) and the rate of sublimation varies among the different salt brands. 


\section{CONCLUSION}

In this study, Dangote salt lost $92.8 \%$ of its original iodine level against $100 \%$ lost by Mr. Chef salt brand at the end of 120 days exposure to room temperature. This indicates that the iodate fortified in the former salt brand is more stable than the later. Ekott and Etukudo (2017) exposed both salt brands to varied high temperatures and obtained similar results on their iodate stability. This indicates that iodate stability in salts varies among different brands, especially with changes in storage temperature and duration. Iodine is an important micro-nutrient required for well-being. Inadequate intake of iodine through diet results in poor mental and physical development in children and goiter in adults (Hassanien et. al, 2003). It is important that salt manufacturers and vendors maintain guidelines needed to prevent health disorders associated with the consumption of salts with little or inadequate iodate, which may be caused by improper handling of the iodized salts.

\section{RECOMMENDATIONS}

In order to maintain the achievement of universal salt iodization (USI) programs in Nigeria and minimize Iodine Deficiency Disorders (IDDs), it is recommended that government agencies (ministry of Health, national agency for food and drugs administration and control, standard organization of Nigeria, including the world health organization) should monitor the production of edible salts at the factory level to ensure compliance with iodization policies. Health awareness programs that target salt producers, marketers and consumers pertaining to proper handling of iodized salt should be embarked on; this will significantly enhance the aim of the universal salt iodization (USI) programs in Nigeria.

\section{REFERENCES}

[1] Bourre, J.M and Paquotte, P. (2008): Seafood (wild and farmed) for the elderly: contribution to the dietary intakes of iodine, selenium, DHA and vitamins B12 and D. J. Nutritional Health Aging. 12 (3):186-92.

[2] Delange F., Burgi H., Chenz Z. P and Dunn J. T. (2002): World Status of monitoring IDD control program. Mary Ann. Liebert Incorporated. 10(12):915 - 924 .

[3] Diosady, L.L; Alberti, J.O; Venkatesh, M; and Fitzgerald, S (1998): Stability of Iodine in Iodized Salt used for Correction of Iodine-deficiency disorders II. Food and Nutrition Bulletin. 19 (3). The United Nations University.

[4] Dr. Srivastava, K. R. (2006) Revised Policy Guidelines on National Iodine Deficiency Disorders Control Programme.

[5] Ekott E.J and Etukudo U.I (2017) Iodine stability in commercial salt brands in Nigeria. Journal of Engineering and Technical Research 7(3):2454-4698.

[6] Fasanmade . O (2019) Iodine Deficiency is a major cause of thyroid disease. The Punch, February, 12th, 2019. Page

[7] Hassanien, M.H; Hussein, L.A; Robinson, E.N and Preston Mercer L (2003): Human iodine requirements determined by the saturation kinetics model. Journal of Nutritional Biochemistry. 14(5):280-7.

[8] Jooste, P.L and Strydom, E. (2010): Methods for determination of iodine in urine and salt. Best Practical Resource Clinical Endocrinal Metabolism. 24(1):77-88.

[9] Khurana I. (2006): Textbook of Medical Physiology; Endocrinal System India: Reed Elsevier. Pages: 710-715.

[10] Ofortube, I. (2019) Iodine Deficiency is a major cause of thyroid disease. The Punch, February, 12th, 2019. Page

[11] WHO/UNICEF/ICCIDD (1996): Recommended Iodine Levels in Salt and Guidelines for Iodine Deficiency Disorders.

[12] Zimmermann, M.B (2009): Iodine deficiency. Endocrine Review 30(4): 376-408 